\title{
Multi-kinase inhibitors and cisplatin for head and neck cancer treatment in vitro
}

\author{
ROMAN C. BRANDS ${ }^{1,2}$, FRANCESCO DE DONNO ${ }^{1}$, MARIE LUISE KNIERIM ${ }^{1}$, VALENTIN STEINACKER ${ }^{1}$, \\ STEFAN HARTMANN $^{1,3}$, AXEL SEHER ${ }^{1}$, ALEXANDER C. KÜBLER ${ }^{1}$ and URS D. A. MÜLLER-RICHTER ${ }^{1}$ \\ ${ }^{1}$ Department of Oral and Maxillofacial Plastic Surgery; ${ }^{2}$ Comprehensive Cancer Center Mainfranken; \\ ${ }^{3}$ Interdisciplinary Center for Clinical Research, University Hospital Würzburg, D-97070 Würzburg, Germany
}

Received August 1, 2018; Accepted March 14, 2019

DOI: $10.3892 / 01.2019 .10541$

\begin{abstract}
Multidrug resistance (MDR) remains one of the major causes of suboptimal outcome following therapy in head and neck squamous cell carcinoma (HNSCC). ATP-binding cassette $(\mathrm{ABC})$ transporters are overexpressed in HNSCC, which contributes to the limited effect of chemotherapeutic treatment. In addition to their named function, tyrosine kinase inhibitors (TKIs) have been revealed to impact on ABC transporter activity and expression. Therefore, the present study aimed to investigate the effects of combination therapy using different TKIs combined with cisplatin. Reverse transcription-quantitative PCR was used to characterize ABC transporter and receptor expression in 5 HNSCC cell lines treated with 3 different TKIs (pazopanib, dovitinib, nintedanib) and cisplatin. Treatment efficacy was analyzed using a crystal violet staining assay. Analysis of ABC transporter (ABCB1, $\mathrm{ABCC} 1$ and $\mathrm{ABCG} 2$ ) genetic alterations was performed using The Cancer Genome Atlas. Statistical analysis was conducted to evaluate the effects of mono- and combination treatment. With the exception of $\mathrm{ABCB} 1$, all of the investigated $\mathrm{ABC}$ transporters were expressed in each cell line. The additive effects of TKI + cisplatin combination treatment were observed for pazopanib in three cell lines, nintedanib in four cell lines, and were not observed for dovitinib in any of the cell lines investigated. The combination of multi-kinase inhibitors and conventional chemotherapy in HNSCC may strengthen the use of current therapeutic strategies; nintedanib appears to be the most suitable TKI for combination therapy. Further efforts are required to classify TKI efficacy with regard to cisplatin resistance.
\end{abstract}

Correspondence to: Dr Roman C. Brands, Department of Oral and Maxillofacial Plastic Surgery, University Hospital Würzburg, 2 Pleicherwall, D-97070 Würzburg, Germany

E-mail: brands_r@ukw.de

Key words: head and neck squamous cell carcinoma, targeted therapy, ATP-binding cassette-transporter, multidrug resistance

\section{Introduction}

According to the Robert Koch Institute, head and neck squamous cell carcinoma (HNSCC) is the sixth most common neoplastic disease, based on $\sim 690,000$ new cases worldwide, and 13,800 new cases per year in Germany (1). Despite advances in surgical, radioactive and molecular treatments, the 5-year overall survival rate of patients with HNSCC remains at $55-60 \%$, with most deaths occurring due to organ failure resulting from multiple metastases, which are often resistant to conventional therapies (2). Notably, $\leq 70 \%$ of chemotherapy regimens for the treatment of HNSCC in the USA include cisplatin, underscoring its efficacy in the treatment of this type of cancer (3). However, acquired chemotherapy resistance is a problem in HNSCC (4), and patients who had previously received chemotherapy demonstrated lower response rates to second-line treatment compared with those who did not (5). A reason for this may be the presence of ATP-binding cassette (ABC) transporters (ABCB1, ABCC1 and ABCG2), which can promote multidrug resistance (MDR) (6). These proteins are known to be overexpressed in several types of tumor, and contribute to chemo-resistance due to their efflux pump function $(7,8)$. Cisplatin has been identified as a substrate for ABCB1, ABCC and ABCG family members (9-11).

During the previous decade, cisplatin-based chemotherapies, which are most often used to treat HNSCC, were expanded to include targeted therapy with monoclonal antibodies and tyrosine kinase inhibitors (TKIs). However, the efficacy of TKIs, which were initially aimed at targeting epidermal growth factor receptor (EGFR), was limited; thus, novel therapeutic targets are being considered. In this context, various agents are applied to disrupt the altered signaling in the tumor microenvironment (TME), which comprises immune cells, the tumor vasculature, lymphatics, pericytes and cancer-associated fibroblasts, in addition to collagens and laminins (12-14). Indeed, the complex interaction between the tumor and the components of the TME is of relevance for cell migration, invasion and metastasis. As revealed in other cancer models, ectopic expression of fibroblast growth factor receptor (FGFR), a primary participant in the TME, markedly enhanced cisplatin resistance (15). Additionally, increased FGF2, FGFR2 and FGFR3 expression levels were observed in HNSCC tissues compared with in normal 
mucosal tissues, suggesting an autocrine influence on HNSCC carcinogenesis (16).

A number of TKIs, which interfere with tumor and micro-environmental interactions, were recently reported to modulate the activity of ABC transporters by directly blocking their efflux function (17). Therefore, the present study aims to investigate whether the TKIs pazopanib, dovitinib and nintedanib are able to enhance cisplatin efficacy in an in vitro model of head and neck cancer.

\section{Materials and methods}

The Cancer Genome Atlas (TCGA) analysis. Sample data for the analysis of MDR transporter mRNA expression in HNSCC was retrieved from TCGA via cBioPortal $(18,19)$. Data for 530 cancer samples were analyzed with regard to genetic alterations in $\mathrm{ABCB} 1, \mathrm{ABCC} 1$ and $\mathrm{ABCG} 2$. Cases with and without alterations were compared in view of overall and median-month survival.

Cell lines. The cell lines used in the present study are listed in Table I. As previously described, the cells were cultured in a humidified atmosphere of $5 \% \mathrm{CO}_{2} / 95 \%$ air at $37^{\circ} \mathrm{C}$, and the culture medium (Dulbecco's Modified Eagle Medium; Thermo Fisher Scientific, Inc.) was changed 2 to 3 times a week (20). The cell lines were established at the Cancer Institute at the University of Pittsburgh (Pittsburgh, PA, USA), and have been used by our group in several studies, particularly in those investigating the cytotoxicity of anti-neoplastic drugs.

Drugs. Pazopanib (Glaxo Smith Kline GmbH and Co.), dovitinib (Novartis Pharma $\mathrm{GmbH}$ ), nintedanib (Boehringer Ingelheim Pharma $\mathrm{GmbH} \& \mathrm{Co}$.) and cisplatin (Accord Healthcare $\mathrm{GmbH}$ ) were purchased from Selleck Chemicals. The targets of these TKIs are listed In Table II.

Crystal violet assay. A crystal violet assay was used to analyze drug efficiency. Following $24 \mathrm{~h}$ of incubation, the cells were exposed to various concentrations ( $\log 2$ and $\log 3$ dilutions) of cisplatin (starting concentration, $400 \mu \mathrm{M}$ ), pazopanib (starting concentration, $800 \mu \mathrm{M}$ ), dovitinib (starting concentration, $200 \mu \mathrm{M}$ ) and nintedanib (starting concentration, $100 \mu \mathrm{M}$ ). Following cell incubation with the respective drugs for $72 \mathrm{~h}$, the medium was removed and the cells were stained with crystal violet ( $1 \mathrm{mg} / \mathrm{ml}$ double distilled water, $20 \%$ methanol) for $12 \mathrm{~min}$. After staining, the supernatant was discarded and the samples were washed several times with water and dried overnight. For absorbance detection using a plate reader (Rainbow Spectra), $100 \mu 1$ methanol was added to each well for $10 \mathrm{~min}$, and the optical density was measured at $595 \mathrm{~nm}$.

RNA isolation, reverse transcription-quantitative PCR $(R T-q P C R)$ and analysis of receptor expression levels. RNA was isolated from cell pellets using an RNeasy ${ }^{\circledR}$ Mini Kit (Qiagen), and the RNA concentration was determined spectrophotometrically at 260/280 nm using the NanoDrop 2000 (Thermo Fisher Scientific, Inc.). cDNA synthesis was performed with $1 \mu \mathrm{g}$ of RNA/probe using the QuantiTect ${ }^{\circledR}$ reverse transcription kit (Qiagen) according to the manufacturer's protocol. Semi-quantitative gene expression levels were evaluated using RT-qPCR with the CFX96 Real-Time PCR Detection System (Bio Rad Laboratories, Inc.). The thermocycling conditions were as follows: Heat activation at $95^{\circ} \mathrm{C}$ for $15 \mathrm{~min}$, followed by 40 cycles of denaturation at $94^{\circ} \mathrm{C}$ for $15 \mathrm{sec}$, annealing at $54^{\circ} \mathrm{C}$ for $30 \mathrm{sec}$ and extension at $72^{\circ} \mathrm{C}$ for $30 \mathrm{sec}$. Amplification was performed using a QuantiTect ${ }^{\circledR}$ SYBR ${ }^{\circledR}$ Green PCR kit (Qiagen) in a total volume of $25 \mu \mathrm{l} /$ probe with $1.5 \mu \mathrm{l}$ gene-specific QuantiTect primers (Qiagen; listed in Table III). The values were derived from three independent experiments. mRNA levels were quantified using the relative expression $\mathrm{RE}(\%)=2^{[\text {Cet st(actin)-Ct(gen)] }} \mathrm{X} 100(21)$ and normalized to $\beta$-actin as the standard, with an assumed expression level of $100 \%$.

Expression levels of $\mathrm{ABC}$ transporters in the cell lines were determined using RT-qPCR, whereby expression was determined as a function of PCR cycles as follows: i) Very strong expression $\geq 0.2$;i) strong expression $=0.1-0.19$; iii) intermediate expression $=0.05-0.09$; and iv) weak expression $\leq 0.04$.

Statistical analysis. The results were derived from three independent experiments, and statistical analysis was conducted using Graph Pad Prism software version 6.05 (GraphPad Software, Inc.). The data are presented as the mean \pm standard error of the mean between biological replicates. $\mathrm{P}<0.05$ was considered to indicate a statistically significant difference, and P-values were categorized according to confidence intervals. Half inhibitory concentration $\left(\mathrm{IC}_{50}\right)$ values (the drug concentration that reduced the colony formation efficiency by $50 \%$ ) were calculated using non-linear regression analysis for mono- and combination treatment. Descriptive statistics were used to illustrate receptor expression. To determine a possible association between the expression level of each transporter and the efficacy of the individual TKI, Pearson's correlation analysis was performed.

\section{Results}

TCGA analysis. Analysis of MDR transporter mRNA expression in patients with HNSCC was conducted using data retrieved from TCGA. A total of 530 cases of HNSCC were analyzed with regard to genetic alterations in $\operatorname{ABCB} 1(18,19)$. The Kaplan-Meier plot shown in Fig. 1 illustrates the overall survival curves for patients with and without ABCB1 alterations. The median overall survival for cases with genetic alterations (32.46 months) was significantly shorter compared with those without alterations (64.78 months; $\mathrm{P}=0.0197)$.

Expression of $A B C B 1, A B C C 1$ and $A B C G 2$. Expression levels of $A B C$ transporters in each of the 5 cell lines were analyzed using RT-qPCR, whereby expression was determined as a function of PCR cycles as follows: i) Very strong expression $\geq 0.2$; ii) strong expression=0.1-0.19; iii) intermediate expression $=0.05-0.09$; and iv) weak expression $\leq 0.04$. As shown in Fig. 2, ABCB1 was detected at weak levels in every cell line except SCC-68, where expression was not detected. In addition, a very strong expression level of ABCC1 was observed in PCI-13 cells, strong expression levels in PCI-1 and PCI-9 cells and intermediate expression levels in PCI-52 and SCC-68 cells. ABCG2 was also detected in each cell line. Although PCI-52 cells exhibited 
Table I. Name, origin and Tumor-Node-Metastasis status of the 5 cell lines used in the study.

Cell line Origin

PCI-1 Derived from a laryngeal carcinoma of the glottis of a male patient. (pT2N00M0G2)

PCI-9 Originated from a primary carcinoma at the base of the tongue of a male patient. (pT4N3M0G2)

PCI-13 Established from an oral squamous cell carcinoma of the retromolar triangle of a male patient. (pT4pN1M0G3)

PCI-52 Derived from a primary carcinoma of the aryepiglottic fold of a male patient. (pT2N0M0G2)

SCC-68 Established from the primary tongue carcinoma of a male patient. (pT4N0M0G1)

Table II. Primary targets of the tyrosine kinase inhibitors pazopanib, dovitinib and nintedanib.

\begin{tabular}{llcccc}
\hline Drug & & Targets & \\
\hline Pazopanib & FGFR1-3 & VEGFR1-3 & PDGFR $\alpha / \beta$ & cKit & cFMS \\
Dovitinib & FGFR1-3 & VEGFR1-4 & - & cKit & FLT-3 \\
Nintedanib & FGFR1-3 & VEGFR1-3 & PDGFR $\alpha / \beta$ & - & - \\
\hline
\end{tabular}

FGFR, fibroblast growth factor receptor; VEGFR, vascular endothelial growth factor receptor; PDGFR, Platelet-derived growth factor receptor; FLT-3, fms-like tyrosine kinase 3; cFMS, colony stimulating factor 1 receptor; cKit, stem cell growth factor receptor.

Table III. Primers used for reverse transcription-quantitative PCR.

\begin{tabular}{lll}
\hline Primer no. & Transporter & Cat. no. \\
\hline 1 & ABCB1 & QT00081928 \\
2 & ABCC1 & QT00061159 \\
3 & ABCG2 & QT00073206 \\
4 & FGFR1 & QT00102837 \\
5 & FGRF2 & QT00098560 \\
6 & FGRF3 & QT01000685 \\
7 & FGRF4 & QT00027636 \\
8 & FLT3 & QT00071316 \\
9 & cKIT & QT00080409 \\
10 & PDGFRA & QT00012719 \\
11 & PDGFRB & QT00082327 \\
12 & VEGFR1 & QT00073640 \\
13 & VEGFR2 & QT00069818 \\
14 & VEGFR3 & QT00063637 \\
15 & c-fms & QT00073276 \\
\hline
\end{tabular}

ABC, ATP-binding cassette; FGFR, fibroblast growth factor receptor; FLT-3, fms-like tyrosine kinase 3; PDGFR, Platelet-derived growth factor receptor; VEGFR, vascular endothelial growth factor receptor; cFMS, colony stimulating factor 1 receptor; cKit, stem cell growth factor receptor.

intermediate expression levels of ABCG2, weak expression was detected in all other cell lines.

Efficacy of cisplatin. Treatment with cisplatin for $72 \mathrm{~h}$ exhibited concentration-dependent effects in all cell lines. The control
Table IV. $\mathrm{IC}_{50}$ values for cisplatin treatment.

\begin{tabular}{lcc}
\hline & ${\text { Calculated } \mathrm{IC}_{50}(\mu \mathrm{M})}$ & Applied $\mathrm{IC}_{50}(\mu \mathrm{M})$ \\
\hline PCI-1 & 0.3 & 1 \\
PCI-9 & 11.1 & 14 \\
PCI-13 & 1.1 & 1 \\
PCI-52 & 4.6 & 5 \\
SCC-68 & 11.9 & 14 \\
\hline IC $_{50}$, half inhibitory concentration. \\
\hline
\end{tabular}

number for each cell line was set to $100 \%$. Applied in a $\log 3$ dilution, cisplatin caused a reduction in cell viability to $9.6 \pm 1 \%$ at a concentration of $44 \mu \mathrm{M}$ in PCI-1 cells, which resulted in an $\mathrm{IC}_{50}$ value of $0.3 \mu \mathrm{M}$. Similar results were observed for PCI-13 and SCC-68 cells, with viable fractions of $9.2 \pm 0.9$ and $12.5 \pm 1.1 \%$, respectively, and $\mathrm{IC}_{50}$ values of 1.1 and $11.9 \mu \mathrm{M}$. By contrast, PCI-9 and PCI-52 cells showed a maximum reduction in the viable fraction to $38.3 \pm 2.3$ and $31 \pm 6.8 \%$, respectively, and the inhibitory concentrations showed a similar range at 11.1 and $4.6 \mu \mathrm{M}$. These results are shown in Fig. 3, and the $\mathrm{IC}_{50}$ values are listed in Table IV.

Efficacy of pazopanib in combination with cisplatin. As shown in Fig. 4, the combination of pazopanib in a $\log 2$ dilution, and cisplatin with the individual $\mathrm{IC}_{50}$ concentration (displayed in Table IV) revealed concentration-dependent effects in all cell lines. In PCI-1 cells, only a small response to combination therapy was detected, which was similar to that revealed for pazopanib mono-therapy. The maximum effect was observed at the highest concentration used, which reduced the viable cell fraction to $46.6 \pm 15.1 \%$ compared with 


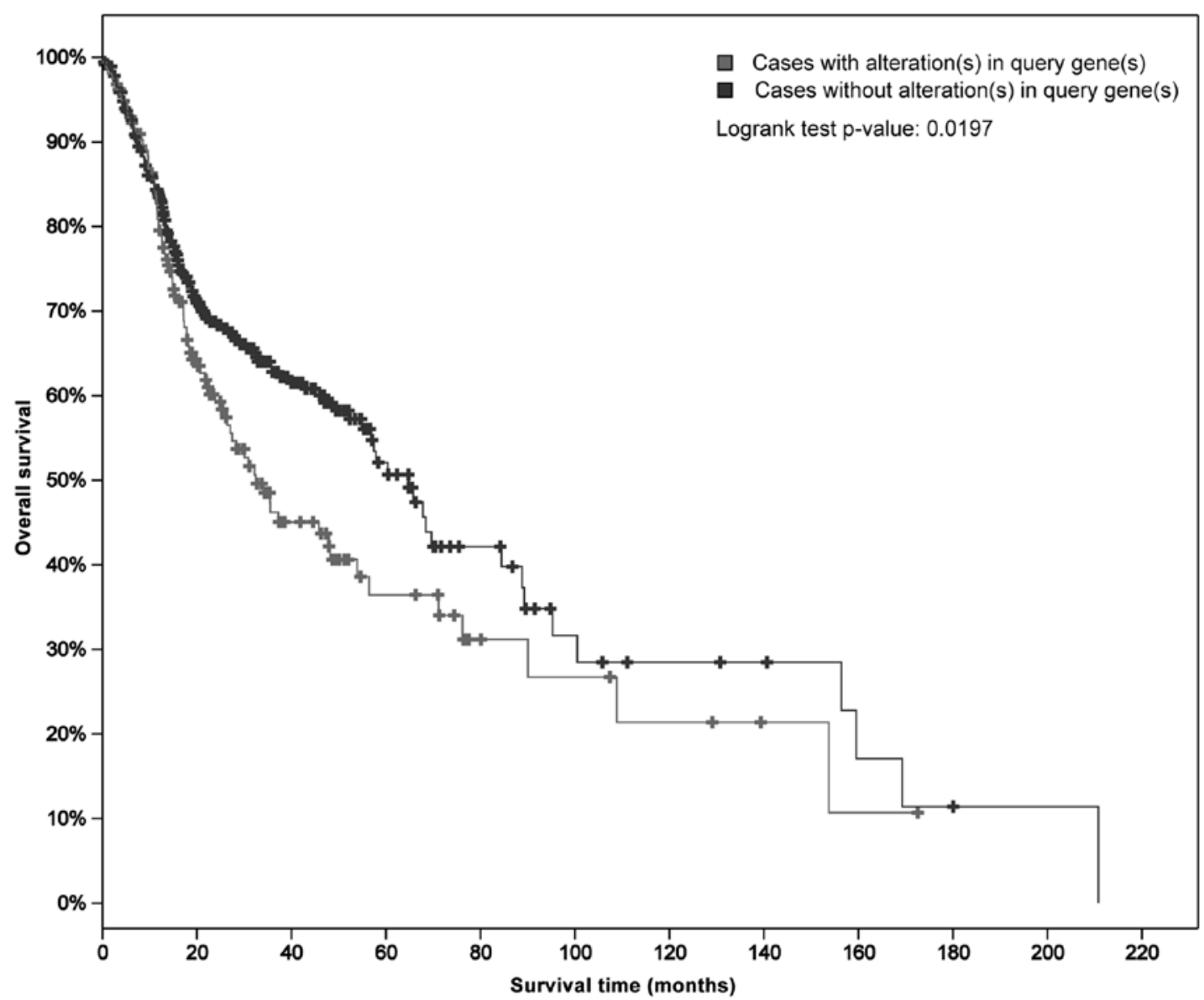

Figure 1. Kaplan-Meier plot illustrating overall survival curves for 530 cases of head and neck squamous cell carcinoma. Overall survival is in regard to the expression ATP-binding cassette transporter B1, with and without genetic alterations. The grey line indicates cases with alterations, and the black line indicates cases without alterations. The median overall survival for the cases with alterations ( 32.46 months) differed significantly from that of cases without alterations (64.78 months; $\mathrm{P}=0.0197)$.

ABCB1
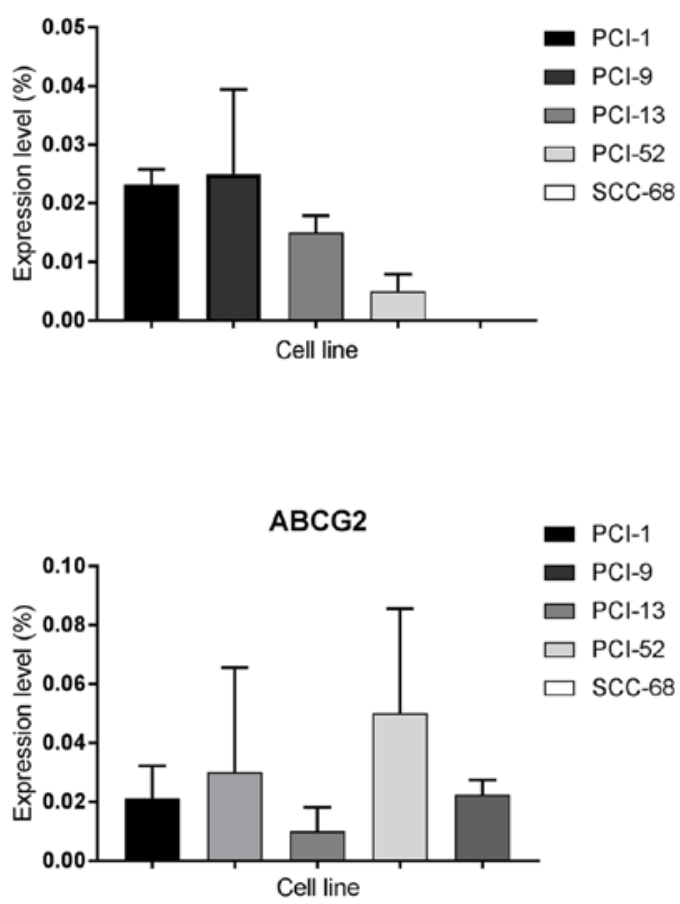

ABCC1

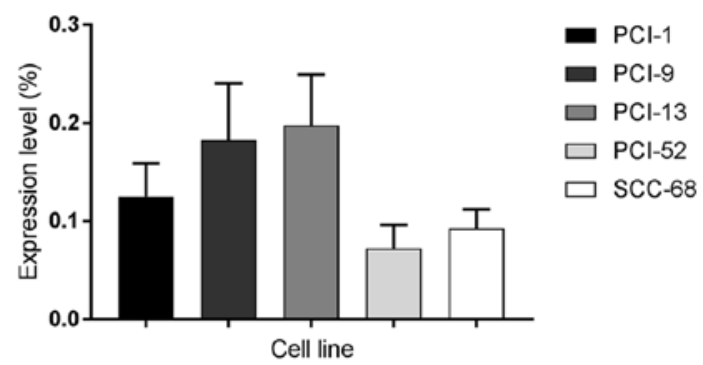

Figure 2. Expression levels of $\mathrm{ABC}$ transporters $\mathrm{ABCB} 1, \mathrm{ABCC} 1$ and $\mathrm{ABCG} 2$ in carcinoma cell lines. Receptor expression is plotted on the $\mathrm{y}-\mathrm{axis}$ as a percentage of the housekeeping gene $\beta$-actin (100\%). ABC, ATP-binding cassette. 
PCl-1

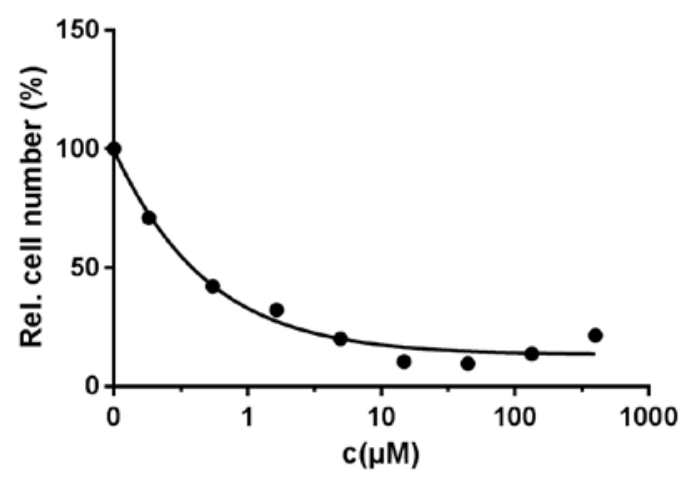

$\mathrm{PCl}-13$

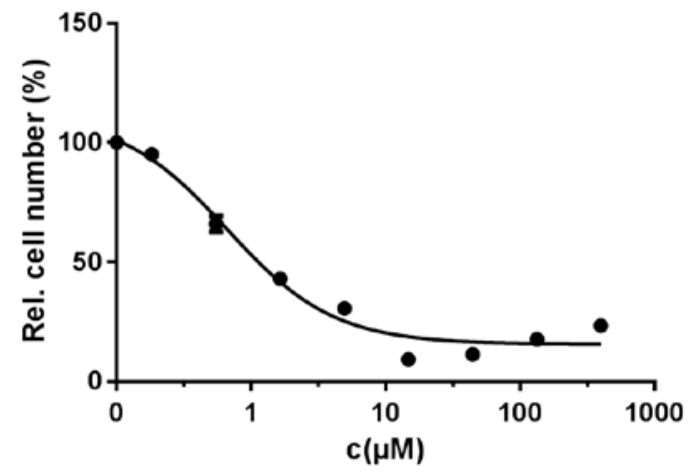

SCC-68

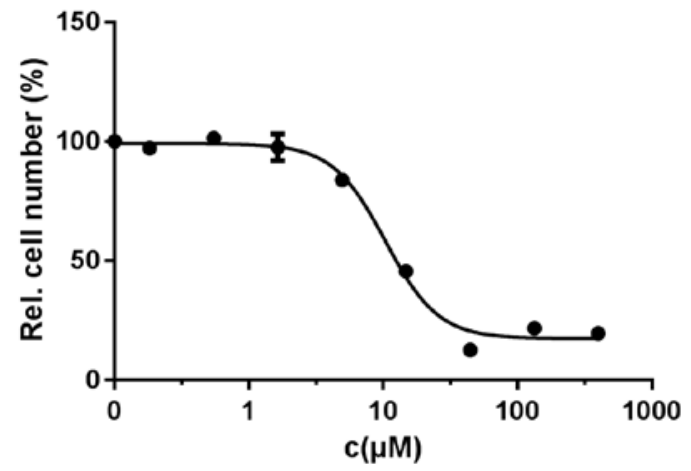

PCl-9

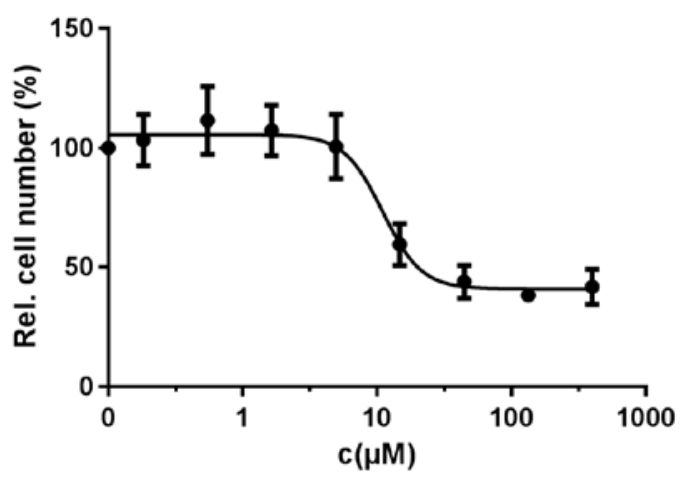

PCI-52

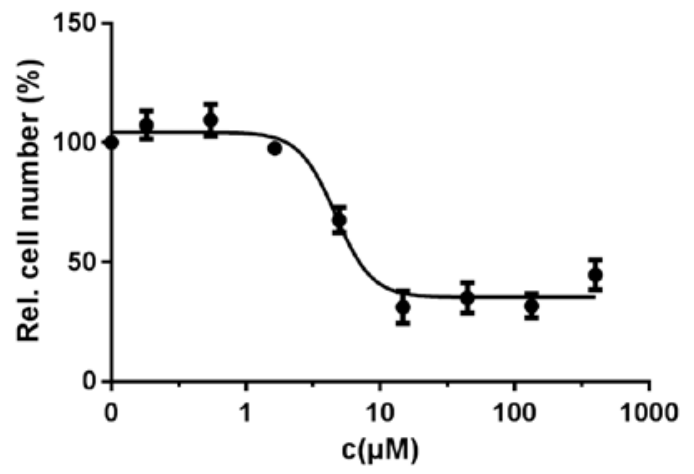

Figure 3. Treatment efficacy of cisplatin (log3 dilution) for the different cell lines (PCI-1, PCI-9, PCI-13, PCI-52 and SCC-68), as determined by crystal violet staining. A concentration-dependent effect was detected in all cell lines.

mono-therapy $(51.3 \pm 3.9 \%)$. The calculated $\mathrm{IC}_{50}$ concentrations for mono- and combination therapy were 11.22 and $10.47 \mu \mathrm{M}$, respectively, and no significant differences were observed. Similar results were obtained for SCC-68 cells. In mono- and combination therapy, SCC-68 cells revealed only a minimal response to TKIs. No distinct differences in the reduction in cell count were illustrated between Pazopanib treatment alone $(62.5 \pm 4.3 \%)$ and that with combination therapy $(64.4 \pm 21.9 \%)$. Additionally, the respective $\mathrm{IC}_{50}$ value of $10.2 \mu \mathrm{M}$ did not change significantly. By contrast, differences between monoand combination therapy were detected in PCI-13 and PCI-52 cells; each cell line exhibited similar reductions in viability following mono- and combination therapy (to $57.9 \pm 4.2$ and $56.7 \pm 12.2 \%$, compared with $84.9 \pm 4.4 \%$ and $94.4 \pm 19.6 \%$ for mono- and combined therapy, respectively), and the calculated
$\mathrm{IC}_{50}$ values were distinctly different $(9.33$ and $34.67 \mu \mathrm{M}$, compared with 20.42 and $26.3 \mu \mathrm{M}$, for mono- and combined therapy, respectively). PCI-9 appeared to be the only cell line that was notably sensitive to combination therapy, with a strong maximum effect in cell count reduction (to 76.9 \pm 7.5 and $50.8 \pm 12.9 \%$ ) and a distinctly lower $\mathrm{IC}_{50}$ value (64.57 and $24.55 \mu \mathrm{M}$ for mono- and combined therapy, respectively). The calculated $\mathrm{IC}_{50}$ values are listed in Table V.

In summary, 2 of the 5 cell lines (PCI-1 and SCC-68) showed no distinct differences in the response to mono- and combination therapy with regard to the reduction in maximum cell count and $\mathrm{IC}_{50}$ concentrations. The other 2 cell lines (PCI-13, PCI-52) exhibited inhibitory effects in response to combination therapy, whereas synergistic effects were only detected in PCI-9 cells. 


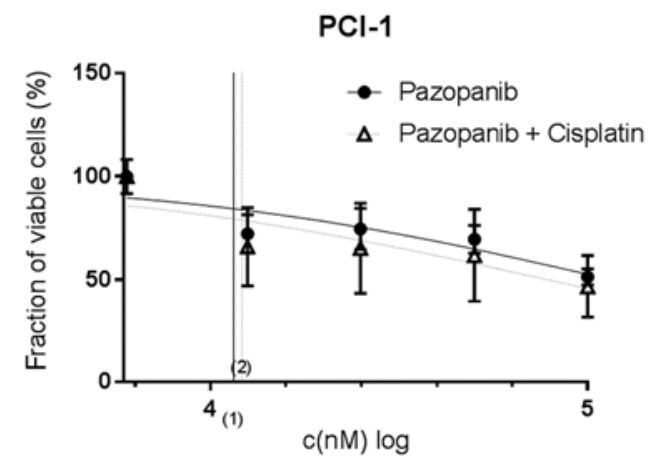

$\mathrm{PCl}-13$

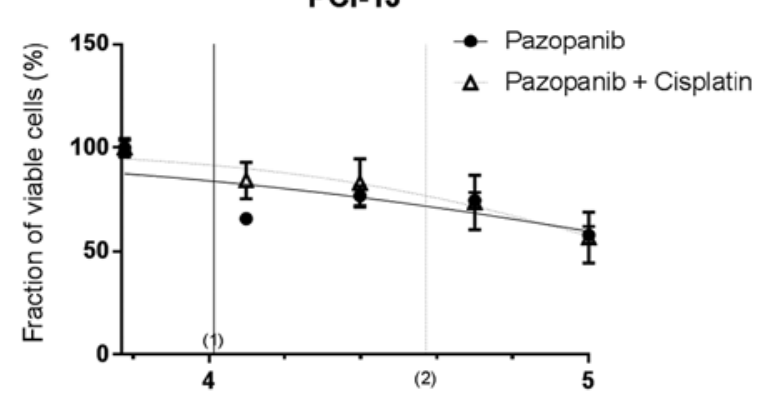

PCl-9

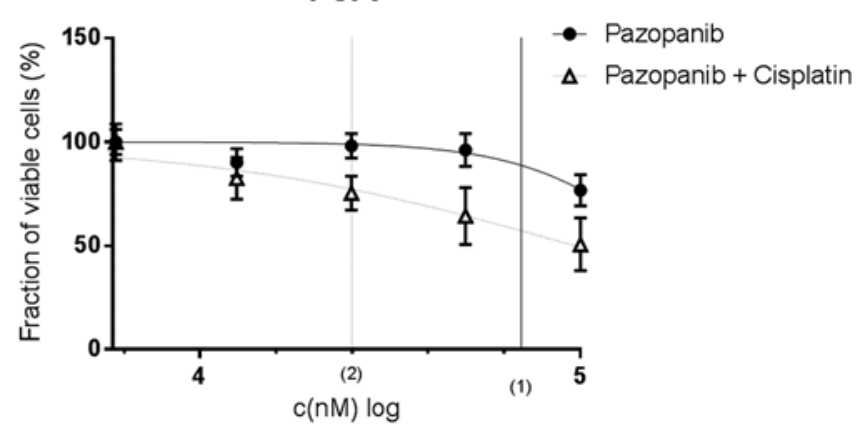

PCI-52

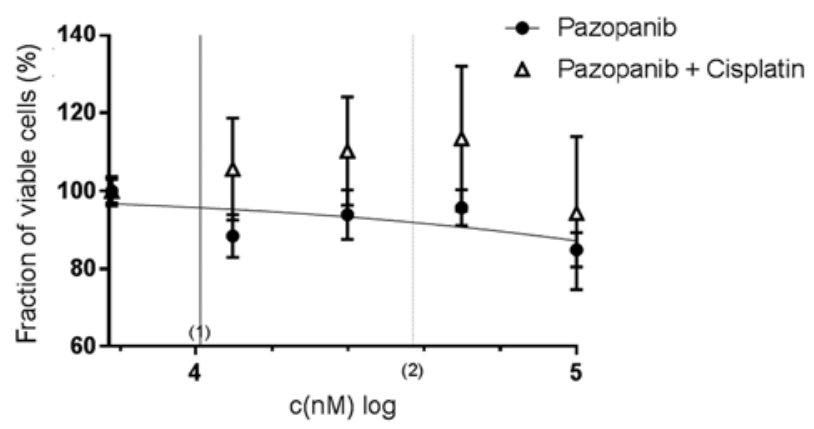

SCC-68

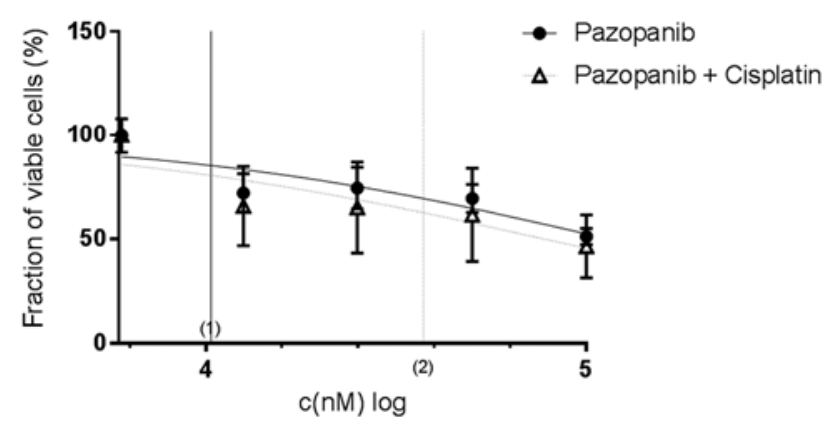

Figure 4. Treatment efficacy of pazopanib and pazopanib + cisplatin in PCI-1, PCI-9, PCI-13, PCI-52 and SCC-68 cell lines. Treatment efficacy was determined using crystal violet staining. The tyrosine kinase inhibitor was administered at a $\log 2$-dilution, and a constant concentration of cisplatin (IC50 value) was added during combination treatment. $\mathrm{IC}_{50}$ values are indicated on the x-axis; (1) indicates mono-therapy, and (2) indicates combination therapy. A concentration-dependent effect was detected in all cell lines. $\mathrm{IC}_{50}$, half inhibitory concentration.

Efficacy of dovitinib in combination with cisplatin. The combination of dovitinib in a $\log 2$ dilution, and cisplatin with its predetermined individual $\mathrm{IC}_{50}$ concentration (Table IV) also exerted concentration-dependent effects in each cell line (Fig. 5). In contrast to pazopanib, distinct differences between mono- and the combination therapy were not detected in any of the cell lines; furthermore, no distinct differences were demonstrated with regard to the $\mathrm{IC}_{50}$ concentrations between the 2 therapy types. In PCI- 1 cells, counts were reduced to $19.5 \pm 3.4 \%$ with mono-therapy, and $6.8 \pm 1.8 \%$ with combination therapy, and only a small difference was detected when comparing the $\mathrm{IC}_{50}$ values (14.13 and $19.95 \mu \mathrm{M}$, respectively). Moreover, minimal differences in inhibitory effects were observed in PCI-13 cells between mono- and combination therapy, with a maximum effect in the range of 7.6 to $10.1 \%$. PCI-52 cells showed similar results, with mono-therapy causing a maximum reduction of the viable fraction to $24.5 \pm 5.8 \%$, and an $\mathrm{IC}_{50}$ concentration of $14.2 \mu \mathrm{M}$, which was not significantly different from that observed following combination therapy. Furthermore, the findings of PCI-9 cells were similar, whereby the maximum reduction of the viable fraction differed marginally between mono- and combination therapy (to $35.9 \pm 12.2$ and $27.1 \pm 3.9 \%$ ). The $\mathrm{IC}_{50}$ values are listed in Table V.

In all of the examined cell lines combination therapy did not exhibit additive or synergistic effects compared with mono treatment.

Efficacy of nintedanib in combination with cisplatin. As shown in Fig. 6, concentration-dependent effects were obtained using nintedanib alone, or in combination with cisplatin. In contrast to pazopanib and dovitinib, markedly synergistic effects were revealed when comparing the effects of mono- and combination therapy, though the effects of mono-therapy and combination therapy did not differ significantly in PCI-1 and PCI-9 cells. In PCI-1 cells, the curve for mono- and combination therapy, 
Table V. Half inhibitory concentrations of pazopanib, dovitinib and nintedanib in mono- and combination therapy with cisplatin.

\begin{tabular}{|c|c|c|c|c|c|c|}
\hline & \multicolumn{2}{|c|}{ Pazopanib $(\mu \mathrm{M})$} & \multicolumn{2}{|c|}{ Dovitinib $(\mu \mathrm{M})$} & \multicolumn{2}{|c|}{ Nintedanib $(\mu \mathrm{M})$} \\
\hline & Mono & Combination & Mono & Combination & Mono & Combination \\
\hline PCI-1 & 11.22 & 10.47 & 14.13 & 19.95 & 5.37 & 4.68 \\
\hline PCI-9 & 64.57 & 24.55 & 8.32 & 15.14 & 5.37 & 5.5 \\
\hline PCI-13 & 9.33 & 34.67 & 6.03 & 15.49 & 23.44 & 5.62 \\
\hline PCI-52 & 20.42 & 26.3 & 14.2 & 18.62 & 17.38 & 8.51 \\
\hline SCC-68 & 11.1 & 10.2 & 7.94 & 12.59 & 29.51 & 5.13 \\
\hline
\end{tabular}

$\mathrm{PCl}-1$

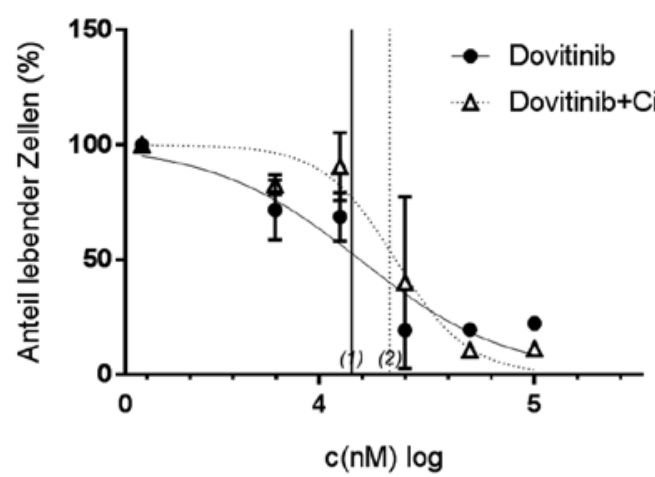

$\mathrm{PCl}-13$

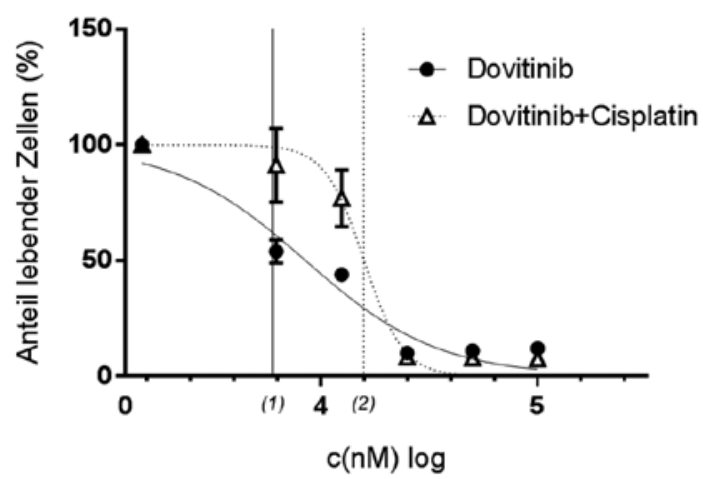

SCC-68

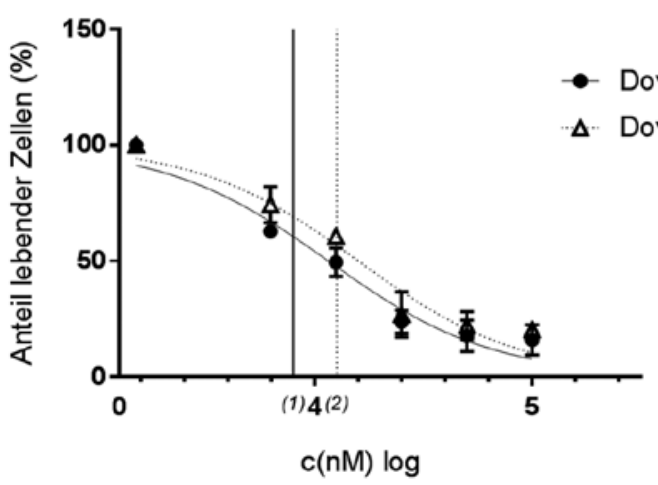

PCI-9

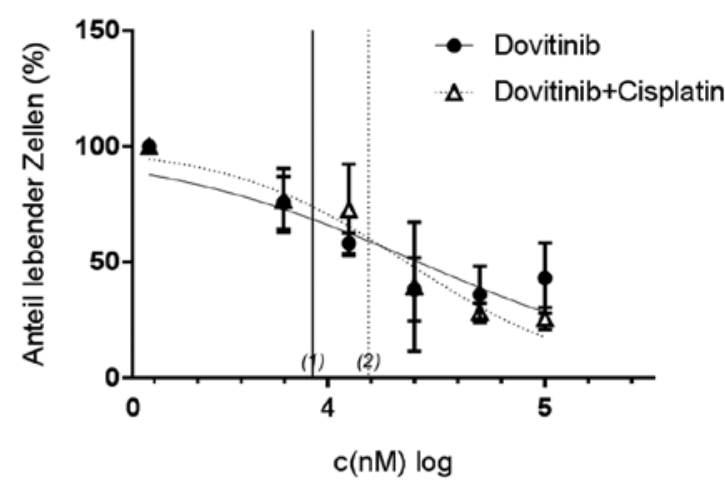

PCI-52

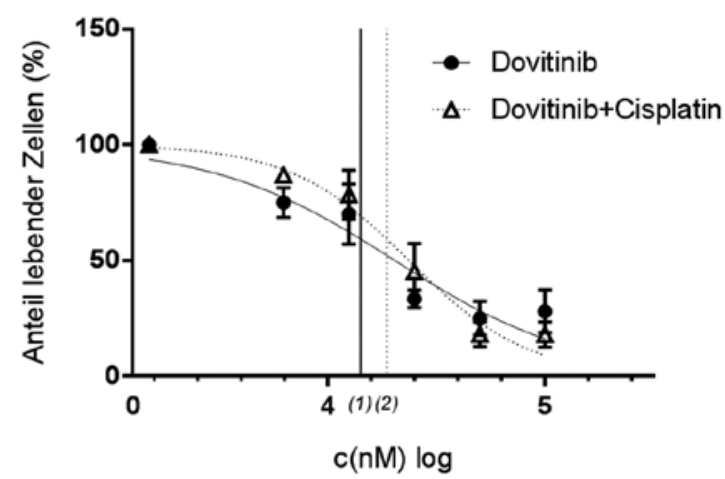

Figure 5. Treatment efficacy of dovitinib and dovitinib + cisplatin in PCI-1, PCI-9, PCI-13, PCI-52 and SCC-68 cell lines. Treatment efficacy was determined using crystal violet staining. The tyrosine kinase inhibitor was administered at a $\log 2$-dilution, and a constant concentration of cisplatin ( $\mathrm{IC}_{50}$ value) was added during combination treatment. $\mathrm{IC}_{50}$ values are displayed on the $\mathrm{x}$-axis; (1) indicates monotherapy, and (2) indicates combination therapy. A concentration-dependent effect was detected in all cell lines. $\mathrm{IC}_{50}$, half inhibitory concentration. 


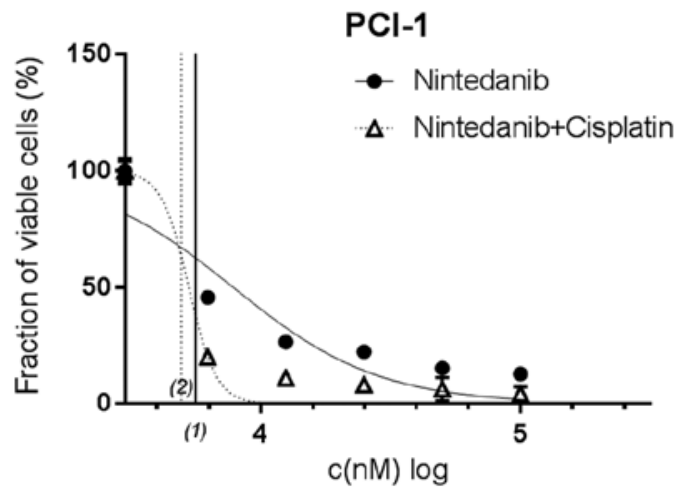

PCl-13

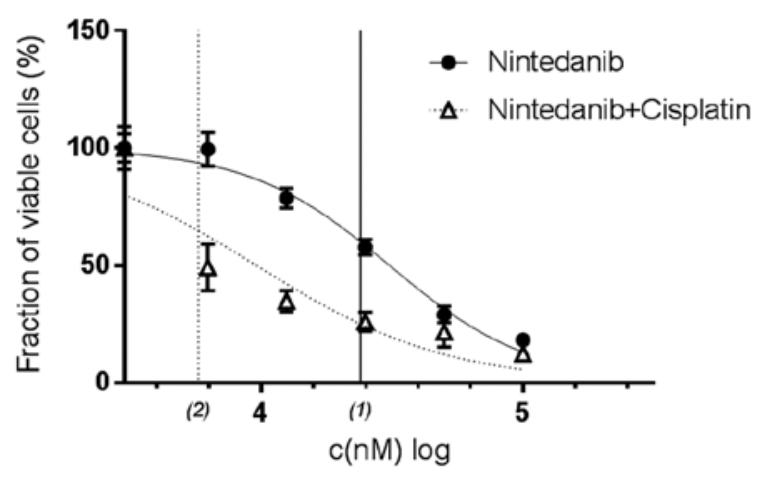

PCl-9

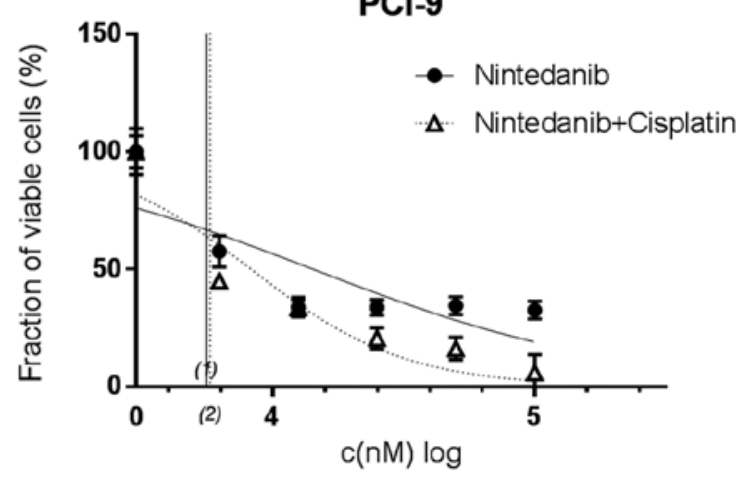

PCl-52

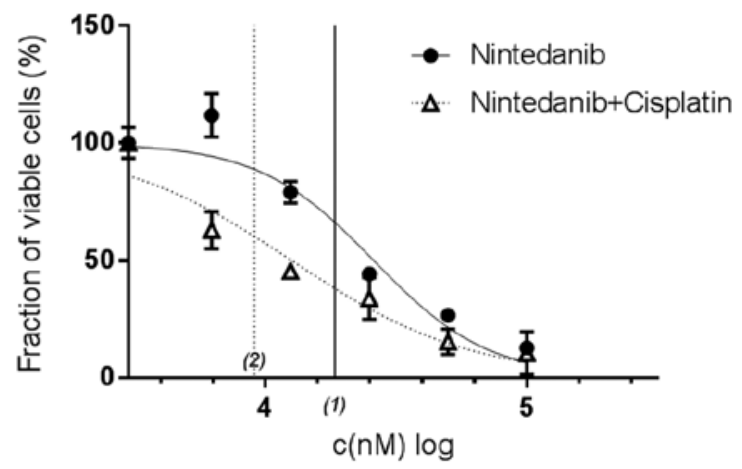

SCC-68

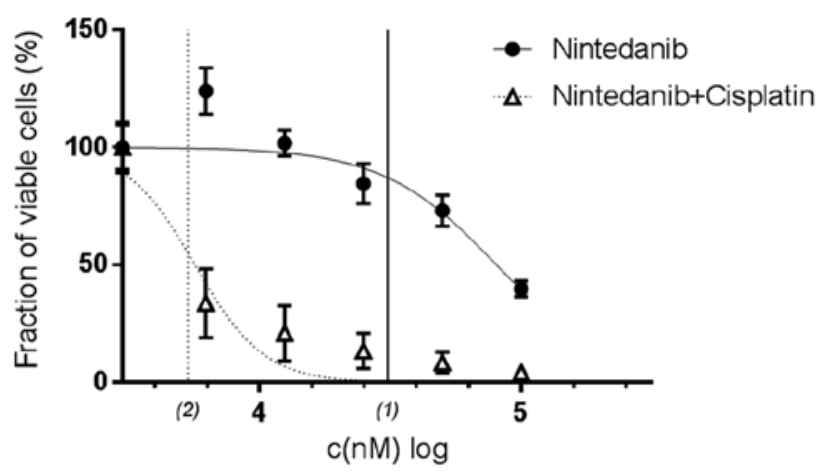

Figure 6. Treatment efficacy of nintedanib and nintedanib + cisplatin in PCI-1, PCI-9, PCI-13, PCI-52 and SCC-68 cell lines. Treatment efficacy was determined using crystal violet staining. The tyrosine kinase inhibitor was administered at a $\log 2$-dilution, and a constant concentration of cisplatin $\left(\mathrm{IC}_{50}\right.$ value) was added for combination treatment. $\mathrm{IC}_{50}$ values are displayed on the $\mathrm{x}$-axis; (1) indicates mono-therapy, and (2) indicates combination therapy. $\mathrm{A}$ concentration-dependent effect was detected in all cell lines. $\mathrm{IC}_{50}$, half inhibitory concentration.

and the respective $\mathrm{IC}_{50}$ concentrations $(5.37$ and $4.68 \mu \mathrm{M})$ were distinctly different. Similar results were demonstrated in PCI-9 cells. Although the viable fraction of cells following mono- and combination differed significantly $(32.6 \pm 3.9$ and $5.9 \pm 7.6 \%)$, the $\mathrm{IC}_{50}$ values $(5.5$ and $5.4 \mu \mathrm{M})$ did not differ remarkably. In PCI-13 cells, the maximum reduction of the viable fraction (to $18.4 \pm 1.6$ and $12.5 \pm 2.5 \%$ ) was nearly the same between mono- and combination therapy, respectively, with the calculated $\mathrm{IC}_{50}$ concentrations $(5.37$ and $5.5 \mu \mathrm{M})$. In the PCI-52 cell line, maximum cell reduction ranged from $10.5 \pm 9.1$ to $12.8 \pm 0.7 \%$, and combination therapy $\mathrm{IC}_{50}$ values revealed synergistic effects (17.38 and $8.51 \mu \mathrm{M})$. With a maximum cell count reduction to
$4.2 \pm 1.9 \%$ and corresponding $\mathrm{IC}_{50}$ values of 29.51 and $5.13 \mu \mathrm{M}$ (mono- and combination therapy, respectively), this effect was more distinct in SCC-68 cells.

In summary, by comparing maximum cell count reductions and respective $\mathrm{IC}_{50}$ concentrations, combination therapy exhibited synergistic effects in four of the five cell lines tested (PCI-1, PCI-13, PCI-52 and SCC-68). One cell line (PCI-9) did not exhibit distinct differences in viability between mono- and combination therapy.

Correlation between $A B C$ transporter expression levels and TKI response. Correlation analysis between $\mathrm{ABC}$ transporter 
Table VI. Correlation analysis between tyrosine kinase inhibitor (pazopanib, dovitinib and nintedanib) responses and ABC transporter expression levels.

ABC Transporter

\begin{tabular}{|c|c|c|c|c|c|c|}
\hline \multirow{2}{*}{$\begin{array}{l}\text { Drug } \\
\text { Pazopanib }\end{array}$} & \multicolumn{2}{|c|}{ ABCB1 } & \multicolumn{2}{|c|}{$\mathrm{ABCC} 1$} & \multicolumn{2}{|c|}{ ABCG2 } \\
\hline & $\mathrm{r}=0.1151$ & $\mathrm{P}=0.8538$ & $\mathrm{r}=-0.3354$ & $\mathrm{P}=0.5812$ & $\mathrm{r}=0.7006$ & $\mathrm{P}=0.1876$ \\
\hline Dovitinib & $\mathrm{r}=0.2809$ & $\mathrm{P}=0.6471$ & $r=-0.6087$ & $\mathrm{P}=0.276$ & $\mathrm{r}=0.6959$ & $\mathrm{P}=0.1918$ \\
\hline Nintedanib & $r=-0.9489$ & $\mathrm{P}=0.0138$ & $\mathrm{r}=-0.09913$ & $\mathrm{P}=0.874$ & $\mathrm{r}=0.1695$ & $\mathrm{P}=0.7853$ \\
\hline
\end{tabular}

ABC, ATP-binding cassette.
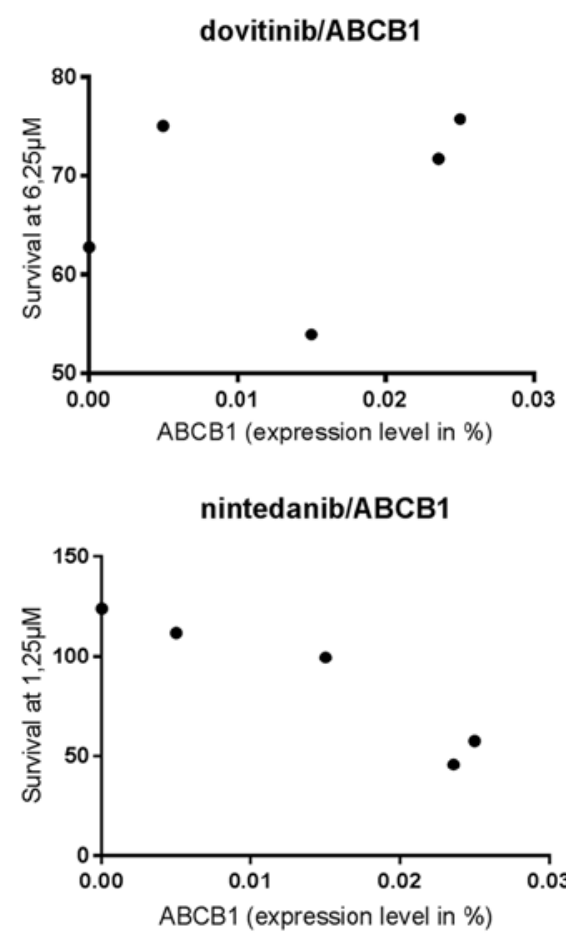

pazopanib/ABCB1

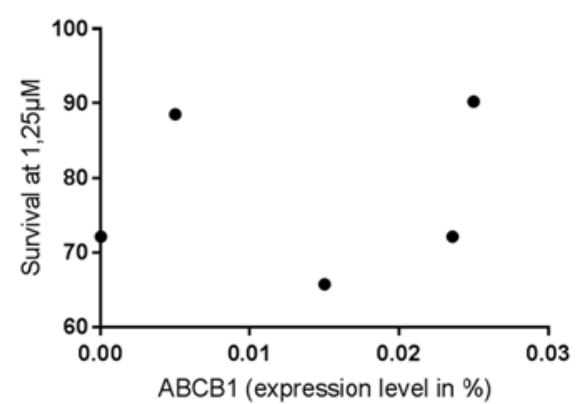

dovitinib/ABCC1

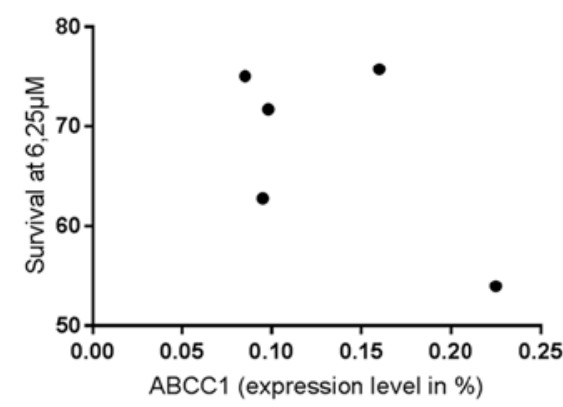

nintedanib/ABCC1

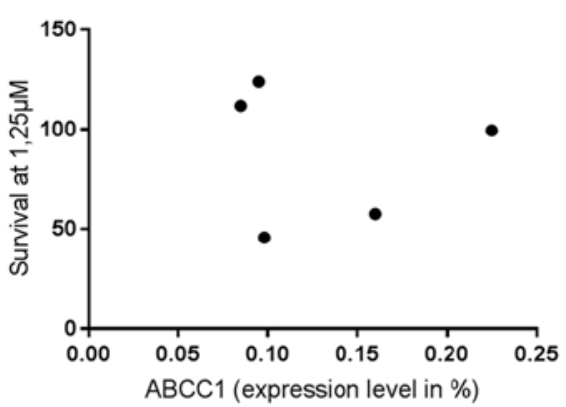

pazopanib/ABCC1

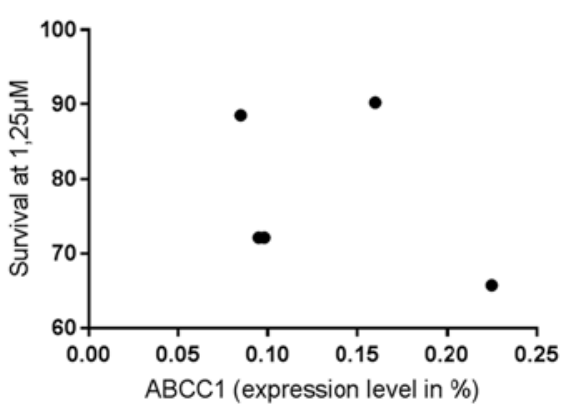

dovitinib/ABCG2

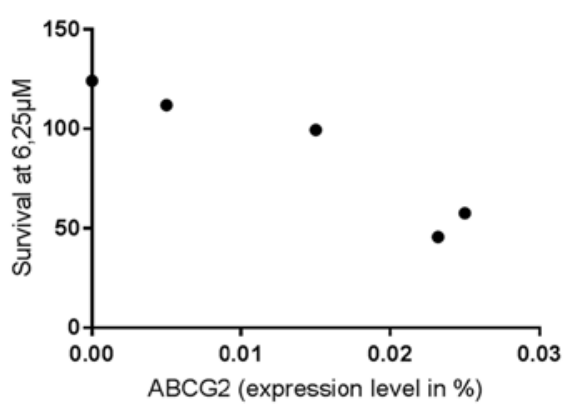

nintedanib/ABCG2

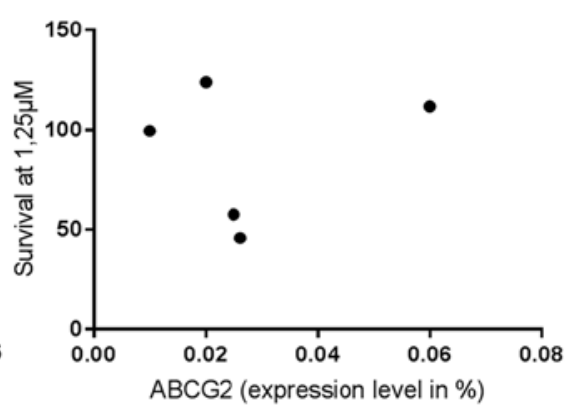

pazopanib/ABCG2

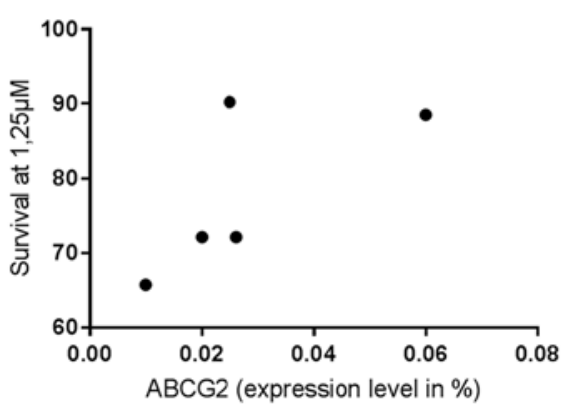

Figure 7. Correlation analysis of tyrosine kinase inhibitors (pazopanib, dovitinib and nintedanib) response and $\mathrm{ABC}$ transporter (ABCB1, $\mathrm{ABCC} 1$ and $\mathrm{ABCG}$ ) expression levels. Transporter expression levels are indicated on the $\mathrm{x}$-axis; surviving fraction on the $\mathrm{y}$-axis. ABC, ATP binding cassette.

expression levels and TKI response was based on the lowest concentrations of the TKI that induced significant cell count reduction (pazopanib: $1.25 \mu \mathrm{M}$, dovitinib: $6.25 \mu \mathrm{M}$, nintedanib: $6.25 \mu \mathrm{M}$ ) and the expression levels of $\mathrm{ABCB} 1, \mathrm{ABCC} 1$ and ABCG2. Pearson's correlation (r) and significance $(\mathrm{P})$ are shown in Table VI. A significant correlation $(\mathrm{P}=0.0138)$ was observed between the nintedanib response and ABCB1 expression level. The other $\mathrm{ABC}$ transporters were not significantly influenced by TKI response in the cell lines tested (Fig. 7).

Expression of receptor tyrosine kinases. As previously described, the expression levels of the respective receptor tyrosine kinases were analyzed using RT-qPCR for each of the 5 cell lines (22). 
VEGFR

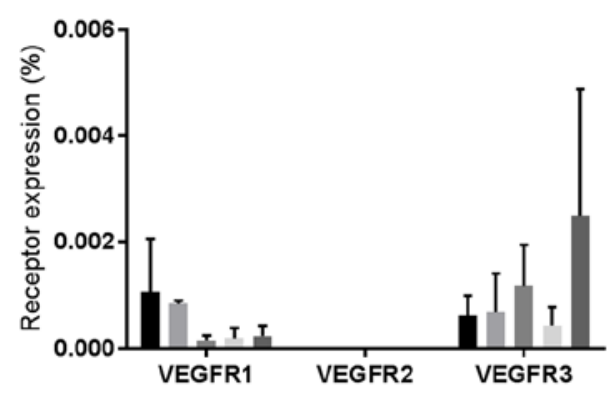

PDGFR

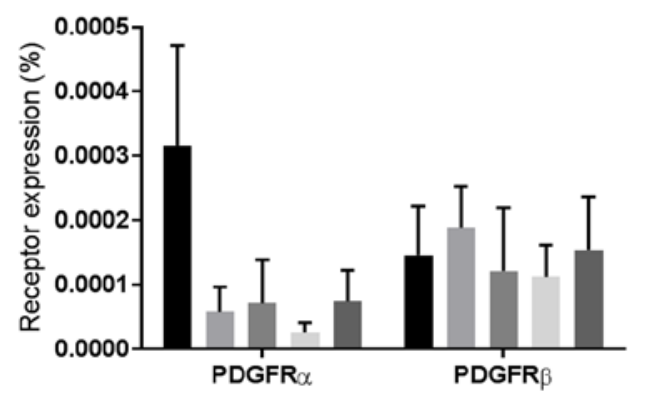

cKit

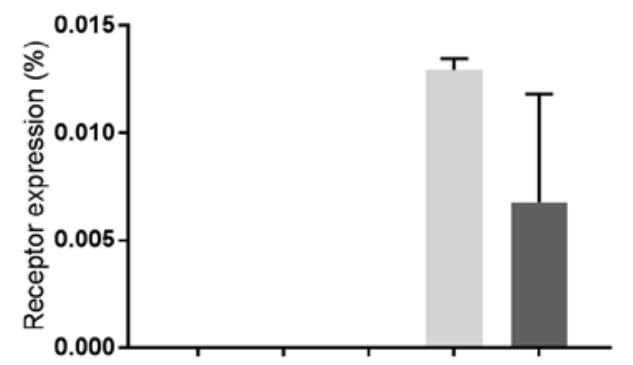

FGFR
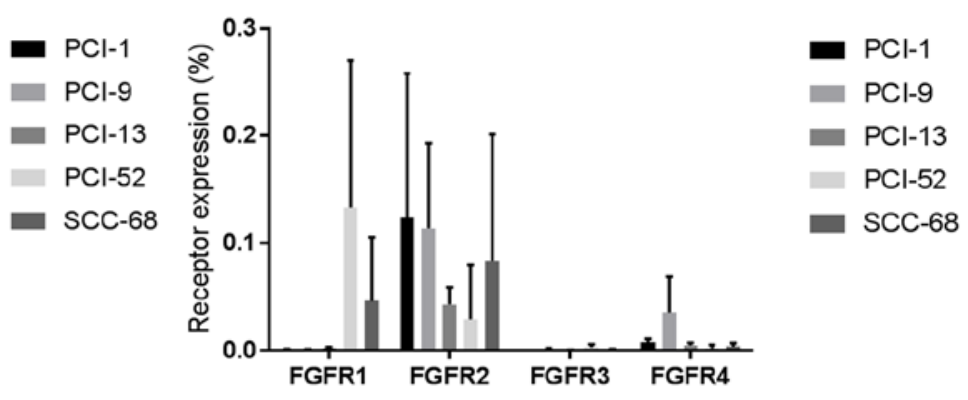

cFMS

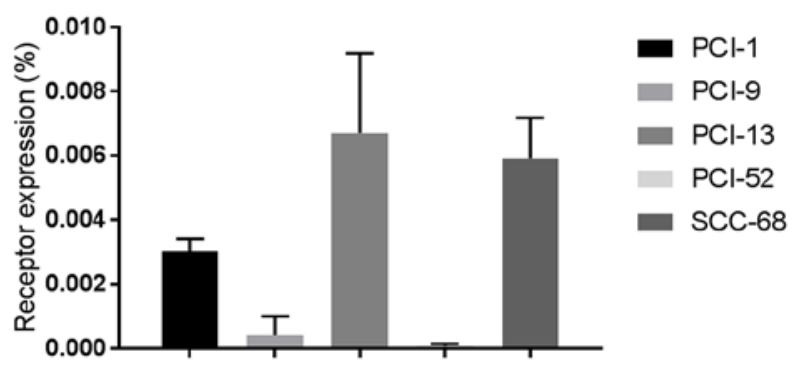

FLT-3

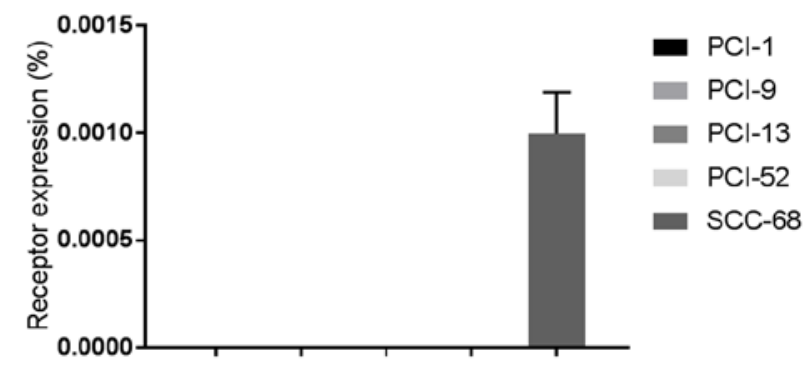

Figure 8. VEGFR1-3, FGFR1-4, PDGFR $\alpha$ and $\beta$, cFMS, cKit and FLT-3 expression in PCI-1, PCI-9, PCI-13, PCI-52 and SCC-68 cell lines. The expression of the receptors is plotted on the $y$-axis as a percentage of the level of the housekeeping gene $\beta$-actin. The expression levels were determined as a function of PCR cycles as follows: i) Very strong expression $\geq 0.1$; ii) strong expression=0.01-0.09; iii) intermediate expression=0.001-0.009; and v) weak expression $\leq 0.0009$. FGFR, fibroblast growth factor receptor; VEGFR, vascular endothelial growth factor receptor; PDGFR, Platelet-derived growth factor receptor; FLT-3, fms-like tyrosine kinase 3; cFMS, colony stimulating factor 1 receptor; cKit, stem cell growth factor receptor.

Expression levels were determined as a function of PCR cycles, as follows: i) Very strong expression $\geq 0.1$; ii) strong expression=0.01-0.09; iii) intermediate expression $=0.001-0.009$; and v) weak expression $\leq 0.0009$. Low and intermediate expression levels of vascular endothelial growth factor receptor (VEGFR) 1 and 3 were exhibited in all of the cell lines, whereas VEGFR2 was only detected in low expression levels in SCC-68 cells. FGFR2 was expressed at high levels in four of the five cell lines (PCI-1, PCI-9, PCI-13, PCI-52 and SCC-68), and FGFR1 was expressed at high levels in PCI-52 and SCC-68 cells. Intermediate and low levels of FGFR3 and FGFR4 were expressed in all five cell lines. Platelet-derived growth factor receptor (PDGFR) $\alpha$ and $\beta$ were only weakly expressed in the five cell lines. Intermediate expression levels of colony stimulating factor 1 receptor were observed in PCI-1, PCI-13 and SCC-68. Stem cell growth factor receptor exhibited strong expression levels in PCI-52 and SCC-68 cells, whereas fms-like tyrosine kinase 3 was detected at intermediate expression levels in SCC-68 cells (Fig. 8).

\section{Discussion}

The results of the present study demonstrated that multi-kinase inhibitors may enhance the efficacy of cisplatin treatment in HNSCC cell lines. This finding highlights an important role for these drugs in addition to their impact on angiogenesis and metastasis.

HNSCC is the sixth most common cancer worldwide, with an increasing incidence. Despite improvements in diagnostics, treatment and follow-up, the 5-year survival rate of 55-60\% has not changed in the last few decades $(1,2)$. As the majority of patients present at an advanced tumor stage, multi-modal treatment, including surgery, radiation and chemotherapy is necessary. In particular, recurrence, locoregional and distant metastasis, and inoperable tumors represent a clinical problem that underscores the importance of chemotherapeutic strategy in this subset of patients $(1,2)$. To date, platinum-based chemotherapy has been used to treat $70 \%$ of HNSCC cases in the USA (3), 
and cisplatin exerts its anti-cancer effects by inducing DNA cross-linking, DNA damage and apoptosis (23). Nonetheless, cisplatin is associated with severe side effects, including ototoxicity, neurotoxicity and myelosuppression $(23,24)$. In addition to these side effects, heterogeneous tumor responses result in poor survival rates, which is partly attributable to neoangiogenesis. Additionally, VEGFR and FGFR signaling is altered in the majority of patients with HNSCC, resulting in tumor growth or neoangiogenesis; this influences the poor prognosis of patients due to associations with nodal metastasis and locoregional recurrence following treatment $(25,26)$. As angiogenesis serves a critical role in tumor growth, inhibition of this process alone is insufficient (27) and other VEGFR-targeted therapies, including bevacizumab, do not have the desired effect. Overall, combination therapy with multi-targeted TKIs and cisplatin may have notable impact on HNSCC therapy.

$\mathrm{ABC}$ transporters appear to influence the prognosis of patients with $\mathrm{HNSCC}(7,8)$ and $\mathrm{ABCB} 1, \mathrm{ABCC} 1$ and $\mathrm{ABCG} 2$ are the most frequently described transporters in MDR (28-30). To date, literature has revealed contradicting data regarding ABC expression levels in patients with HNSCC (31-33); in the present study, TCGA analysis revealed that genetic alterations in $\mathrm{ABCB} 1$ occur in $30 \%$ of HNSCC cases, resulting in a significant decrease in overall survival $(\mathrm{P}=0.0197)(18,19)$.

Because TKIs have the potential to influence ABC transporter expression and function, combination therapy with cisplatin is a reasonable choice. Different MDR ABC transporter mRNA levels in cell lines may provide evidence for variable responses to TKI treatment. For example, in the present study, additive effects as a result of combination treatment were observed, with nintedanib showing the most striking additive effects in 4 of the 5 cell lines tested. Correlation analysis for TKI and $\mathrm{ABC}$ transporter expression shows a significant association $(\mathrm{P}=0.0138)$ between the nintedanib response and ABCB1 expression levels. However, it is difficult to draw conclusions about the superiority of nintedanib in combination treatment based on tyrosine kinase receptor expression levels. Nonetheless, there is clear evidence of a possible interaction between TKI and ABC transporters, as the respective TKIs specifically influence the expression level and activity of efflux pumps. It has been reported that nintedanib may inhibit ABCB1/ABCG2 mRNA expression and the ATPase activity of these transporters (34). Weiss et al (35) reported that dovitinib is only a weak inhibitor of $\mathrm{ABCB} 1$ protein function, but that it induces ABCG2 at low concentrations. By contrast, pazopanib exhibits little interaction with $\mathrm{ABCB} 1$ (36) but is a substrate to both $\mathrm{ABCB} 1$ and $\mathrm{ABCG} 2(37,38)$. There appear to be no data regarding the interaction of $\mathrm{ABCC} 1$ and the TKIs investigated.

In a clinical setting, combination therapy with TKIs causes distinct side effects. Reports from Galsky et al (39) revealed poor tolerance to dovitinib in combination with gemcitabine and cisplatin, or gemcitabine and carboplatin in patients with advanced solid tumors due to myelosuppression. Despite the severe side effects associated with multi-targeted TKIs (even in mono-therapy), their effects on neoangiogenesis and metastasis cannot be dismissed.

In conclusion, combination therapy with TKIs and cisplatin appears to be a reasonable approach for HNSCC treatment. Nevertheless, the results require further critical consideration; in the present study, the cells were treated outside of their normal surroundings, without interactions with the TME. Further investigation is required to determine the true efficacy of combination treatments for HNSCC.

\section{Acknowledgements}

Not applicable.

\section{Funding}

The present study was supported by the Comprehensive Cancer Center Mainfranken (R. Brands) and the Interdisciplinary Center for Clinical Research (S. Hartmann).

\section{Availability of data and materials}

The datasets used and/or analyzed during the present study are available from the corresponding author on reasonable request. Additionally, data are available at cbioportal.org, as previously described.

\section{Authors' contributions}

RCB performed the experiments, analyzed data and wrote the manuscript. FDD, MLK and VS performed cell culture experiments. SH, AK and UMR analyzed data and wrote the manuscript. AS performed cell culture experiments and analyzed the data. All authors read and approved the final version of the manuscript.

\section{Ethics approval and consent to participate}

Not applicable.

\section{Patient consent for publication}

Not applicable.

\section{Competing interests}

The authors declare that they have no competing interests.

\section{References}

1. Kamangar F, Dores GM and Anderson WF: Anderson, Patterns of cancer incidence, mortality, and prevalence across five continents: Defining priorities to reduce cancer disparities in different geographic regions of the world. J Clin Oncol 24: 2137-2150, 2006.

2. Langley RR and Fidler IJ: Tumor cell-organ microenvironment interactions in the pathogenesis of cancer metastasis. Endocr Rev 28: 297-321, 2007.

3. Ang KK, Chen A, Curran WJ Jr, Garden AS, Harari PM, Murphy BA, Wong SJ, Bellm LA, Schwartz M, Newman J, et al: Head and neck carcinoma in the United States: First comprehensive report of the longitudinal oncology registry of head and neck carcinoma (LORHAN). Cancer 118: 5783-5792, 2012.

4. Theile D, Gal Z, Warta R, Rigalli JP, Lahrmann B, Grabe N, Herold-Mende C, Dyckhoff G and Weiss J: Antiproliferative efficacies but minor drug transporter inducing effects of paclitaxel, cisplatin, or 5-fluorouracil in a murine xenograft model for head and neck squamous cell carcinoma. Cancer Biol Ther 15: 436-442, 2014.

5. Fanucchi $M$ and Khuri FR: Chemotherapy for recurrent or metastatic squamous cell carcinoma of the head and neck. Semin Oncol 31: 809-815, 2004. 
6. Shen DW, Pouliot LM, Hall MD and Gottesman MM: Cisplatin resistance: A cellular self-defense mechanism resulting from multiple epigenetic and genetic changes. Pharmacol Rev 64: 706-721, 2012

7. Doyle LA, Yang W, Abruzzo LV, Krogmann T, Gao Y, Rishi AK and Ross DD: A multidrug resistance transporter from human MCF-7 breast cancer cells. Proc Natl Acad Sci USA 95: 15665-15670, 1998.

8. Sauerbrey A, Sell W, Steinbach D, Voigt A and Zintl F: Expression of the BCRP gene (ABCG2/MXR/ABCP) in childhood acute lymphoblastic leukaemia. Br J Haematol 118: 147-150, 2002.

9. Borst P, Evers R, Kool M and Wijnholds J: A family of drug transporters: the multidrug resistance-associated proteins. J Nat Cancer Inst 92: 1295-1302, 2000.

10. Fletcher JI, Haber M, Henderson MJ and Norris MD: ABC transporters in cancer: More than just drug efflux pumps. Nat Rev Cancer 10: 147-156, 2010.

11. Silva R, Vilas-Boas V, Carmo H, Dinis-Oliveira RJ, Carvalho F, de Lourdes Bastos M and Remião F: Modulation of P-glycoprotein efflux pump: induction and activation as a therapeutic strategy. Pharmacol Ther 149: 1-123, 2015.

12. Balkwill FR, Capasso M and Hagemann T: The tumor microenvironment at a glance. J Cell Sci 125: 5591-5596, 2012.

13. Hartmann S, Bhola NE and Grandis JR: HGF/Met Signaling in Head and Neck Cancer: Impact on the Tumor Microenvironment. Clin Cancer Res 22: 4005-4013.

14. Quail DF, Taylor MJ and Postovit LM: Microenvironmental regulation of cancer stem cell phenotypes. Curr Stem Cell Res Ther 7: 197-216, 2012.

15. Miyake H, Hara I, Gohji K, Yoshimura K, Arakawa S and Kamidono S: Expression of basic fibroblast growth factor is associated with resistance to cisplatin in a human bladder cancer cell line. Cancer Lett 123: 121-126, 1998.

16. Wakulich C, Jackson-Boeters L, Daley TD and Wysocki GP Immunohistochemical localization of growth factors fibroblast growth factor- 1 and fibroblast growth factor- 2 and receptors fibroblast grow th factor receptor- 2 and fibroblast growth factor receptor-3 in normal oral epithelium, epithelial dysplasias, and squamous cell carcinoma. Oral Surg Oral Med Oral Pathol Oral Radiol Endod 93: 573-579, 2002.

17. Patel A, Tiwari AK, Chufan EE, Sodani K, Anreddy N, Singh S, Ambudkar SV, Stephani R and Chen ZS: PD173074, a selective FGFR inhibitor, reverses ABCB1-mediated drug resistance in cancer cells. Cancer Chemother Pharmacol 72: 189-199, 2013

18. Cerami E, Gao J, Dogrusoz U, Gross BE, Sumer SO, Aksoy BA, Jacobsen A, Byrne CJ, Heuer ML, Larsson E, et al: The cBio cancer genomics portal: An open platform for exploring multidimensional cancer genomics data. Cancer Discov 2: 401-404, 2012.

19. Gao J, Aksoy BA, Dogrusoz U, Dresdner G, Gross B, Sumer SO, Sun Y, Jacobsen A, Sinha R, Larsson E, et al: Integrative analysis of complex cancer genomics and clinical profiles using the cBioPortal. Sci Signal 6: pl1, 2013.

20. Brands RC, Herbst F, Hartmann S, Seher A, Linz C, Kübler AC and Müller-Richter UDA: Cytotoxic effects of SMAC-mimetic compound LCL161 in head and neck cancer cell lines. Clin Oral Investig 20: 2325-2332, 2016.

21. Schmittgen TD and Livak KJ: Analyzing real-time PCR data by the comparative C(T) method. Nat Protoc 3: 1101-1108, 2008.

22. Brands RC, Knierim LM, De Donno F, Steinacker V, Hartmann S, Seher A, Kübler AC and Müller-Richter UDA: Targeting VEGFR and FGFR in head and neck squamous cell carcinoma in vitro. Oncol Rep 38: 1877-1885, 2017.
23. Lee JG and Wu R: Erlotinib-cisplatin combination inhibits growth and angiogenesis through c-MYC and HIF-1 $\alpha$ in EGFR-mutated lung cancer in vitro and in vivo. Neoplasia 17: 190-200, 2015.

24. Tsang RY, Al-Fayea T and Au HJ: Cisplatin overdose: Toxicities and management. Drug Saf 32: 1109-1122, 2009.

25. Sweeny L,Zimmermann TM, Liu Zand Rosenthal EL: Evaluation of tyrosine receptor kinases in the interactions of head and neck squamous cell carcinoma cells and fibroblasts. Oral Oncol 48: $1242-1249,2012$

26. Homer JJ, Greenman J and Stafford ND: Angiogenesis in head and neck squamous cell carcinoma. Clin Otolaryngol Allied Sci 25: 169-180, 2000

27. Cao Y: Antiangiogenic cancer therapy: Why do mouse and human patients respond in a different way to the same drug? Int J Dev Biol 55: 557-562, 2011.

28. Callaghan R: Providing a molecular mechanism for P-glycoprotein; why would I bother? Biochem Soc Trans 43: 995-1002, 2015.

29. Coyle B, Kessler M, Sabnis DH and Kerr ID: ABCB1 in children's brain tumours. Biochem Soc Trans 43: 1018-1022, 2015.

30. Hlaváč V and Souček P: Role of family D ATP-binding cassette transporters (ABCD) in cancer. Biochem Soc Trans 43: 937-942, 2015.

31. Chen CL, Sheen TS, Lou IU and Huang AC: Expression of multidrug resistance 1 and glutathione-S-transferase-Pi protein in nasopharyngeal carcinoma. Hum Pathol 32: 1240-1244, 2001.

32. Lo Muzio L, Staibano S, Pannone G, Mignogna MD, Serpico R, Rubini C, Fioroni M, Fanali S and Piattelli A: The human multidrug resistance gene (MDR-1): Immunocytochemical detection of its expression in oral SCC. Anticancer Res 20: 2891-2897, 2000.

33. Uematsu T, Hasegawa T, Hiraoka BY, Komatsu F, Matsuura T, Yamada AS and Yamaoka M: Multidrug resistance gene 1 expression in salivary gland adenocarcinomas and oral squamous-cell carcinomas. Int J Cancer 92: 187-194, 2001.

34. Xiang QF, Wang F, Su XD, Liang YJ, Zheng LS, Mi YJ, Chen WQ and Fu LW: Effect of BIBF 1120 on reversal of ABCB1-mediated multidrug resistance. Cell Oncol (Dordr) 34: 33-44, 2011.

35. Weiss J, Theile D, Dvorak Z and Haefeli WE: Interaction potential of the multitargeted receptor tyrosine kinase inhibitor dovitinib with drug transporters and drug metabolising enzymes assessed in vitro. Pharmaceutics 6: 632-650, 2014.

36. Roche S, Pedersen K, Dunne G, Collins D, Devery A, Crown J, Clynes $\mathrm{M}$ and O'Connor R: Pharmacological interactions of TKIs with the P-gp drug transport protein. J Clin Oncol 30: 2536-2536, 2012.

37. Atkinson A Jr., Huang SM, Lertora JJL and Markey SP: Principles of clinical pharmacology. Vol. 3 pp 217-237, Academic Press, Cambridge, MA, USA, 2012.

38. Mandery K, Glaeser H and Fromm MF: Interaction of innovative small molecule drugs used for cancer therapy with drug transporters. Br J Pharmacol 165: 345-362, 2012.

39. Galsky MD, Posner M, Holcombe RF, Lee KM, Misiukiewicz K, Tsao CK, Godbold J, Soto R, Gimpel-Tetra K, Lowe N and Oh WK: Phase Ib study of dovitinib in combination with gemcitabine plus cisplatin or gemcitabine plus carboplatin in patients with advanced solid tumors. Cancer Chemother Pharmacol 74: 465-471, 2014.

This work is licensed under a Creative Commons Attribution-NonCommercial-NoDerivatives 4.0 International (CC BY-NC-ND 4.0) License. 